\title{
NIETZSCHE Y SCHOPENHAUER: SOBRE LOS CONCEPTOS Y LOS SIGNOS
}

Nietzsche and Schopenhauer: On concepts and signs

\author{
João Constâncio
}

Universidad Lisboa Nueva

\begin{abstract}
RESUMEN: El objetivo de este artículo es indicar muy sucintamente que mediante la comprensión de las semejanzas y diferencias de Nietzsche respecto a los puntos de vista de Schopenhauer sobre los conceptos y los signos, se puede ver claramente la forma en que trata de superar algunos de los enigmas epistemológicos y ontológicos más importantes de la modernidad; es decir, por qué su filosofía, en muchos aspectos, puede ser vista ya como «contemporánea» o «actual». El artículo presenta primero seis tesis de Schopenhauer sobre los conceptos y los signos, después seis tesis de Nietzsche que pueden parecer idénticas a las de Schopenhauer, pero que acaban siendo radicalmente diferentes. Mi tesis principal es que la concepción nietzscheana de las palabras y de los conceptos en términos de «signos» le debe mucho a Schopenhauer, y sin embargo, representa, en definitiva, un cambio radical del punto de vista de Schopenhauer y de toda la filosofía moderna.

Palabras clave: concepto - signo - Schopenhauer - palabra
\end{abstract}

ABSTRACT: The aim of this paper is to show that by interpreting the similarities and differences between Nietzsche and Schopenhauer's views on concepts and signs one can clearly see how Nietzsche attempts to overcome some of the most fundamental problems of epistemology and ontology raised in modernity - that is to say, why his philosophy is, in many respects, already «contemporaneous». I start by presenting six of Schopenhauer's main theses on concepts and signs and then six parallel theses put forward by Nietzsche. The latter may seem to be identical to the former, but in the end they prove to be radically different. My main point is that Nietzsche's conception of words and concepts in terms of «signs» owes a great deal to Schopenhauer - and yet it represents a radical shift of perspective in relation to Nietzsche's «master» and indeed in relation to the whole of modern philosophy.

Keywords: Concept - Sign - Schopenhauer - Word

1

El objetivo de este trabajo es indicar muy sucintamente que mediante la comprensión de las semejanzas y diferencias de Nietzsche respecto a los puntos de vista de Schopenhauer sobre los conceptos y los signos, se puede ver claramente la forma en que trata de superar algunos de los enigmas epistemológicos y ontológicos más importantes de la modernidad; es decir, por qué su filosofía, en muchos aspectos, puede ser vista ya como «contemporánea»o «actual». 
Presento primero seis tesis de Schopenhauer, después seis tesis de Nietzsche que pueden parecer idénticas a las de Schopenhauer, pero que acaban siendo radicalmente diferentes, es decir, que son en realidad una crítica a las tesis de Schopenhauer y una radicalización de ellas. Mi tesis principal es que la concepción nietzscheana de las palabras y de los conceptos en términos de «signos» le debe mucho a Schopenhauer, y sin embargo representa, en definitiva, un cambio radical del punto de vista de Schopenhauer. Señalo que esto es una pequeña parte -y una parte superficial - de un estudio más vasto de la difícil cuestión de la relación entre Schopenhauer y Nietzsche en la madurez de Nietzsche ${ }^{1}$.

1. Según Schopenhauer, las palabras son «signos de los conceptos». Las palabras «expresan» conceptos ${ }^{2}$, y el discurso no es «nada más que un telégrafo muy completo que comunica signos arbitrarios con la mayor rapidez y la mejor diferencia de matices de significado» ${ }^{3}$. Las palabras son, en suma, una forma abreviada y rápida de comunicar conceptos.

2. Teniendo en cuenta que, para Schopenhauer, la razón es la facultad cognitiva que permite la «formación del concepto» ${ }^{4}$, la razón y el lenguaje son prácticamente idénticos y, por tanto, los conceptos y los signos son inseparables de la «comunicación». Escribe Schopenhauer: «El discurso es el primer producto y la herramienta necesaria de la [humana] facultad de razonar ${ }^{5}$. Las palabras y el lenguaje, como herramientas de la razón humana, hacen posible «la comunicación» ${ }^{6}$, y la comunicación es el mayor logro de la razón humana ${ }^{7}$.

3. Con la razón y el lenguaje, es decir, con conceptos y signos, «una conciencia completamente nueva ha surgido ${ }^{8}$. La idea aquí es que hay diferentes grados de conciencia. La conciencia humana es solo el más alto grado de conciencia, y consiste en representación intuitiva complementada con conceptualización y lenguaje (es decir, con la formación de conceptos y el uso de signos). De ahí que la differentia specifica de los seres humanos es la formación de conceptos y el uso de signos (o sea, la «reflexión», la «abstracta» o «conceptual» representación por medio de los signos lingüísticos, sobre la base de las representaciones intuitivas), y no la conciencia como tal.

1. Cf. João Constâncio, «On Consciousness: Nietzsche's Departure from Schopenhauer»: Nietzsche-Studien 40 (2011), 1-42, y João Constâncio, "Consciousness, Communication, and SelfExpression: Towards an Interpretation of Aphorism 354 of Nietzsche's The Gay Science», en J. Constâncio y M. Branco (eds.), As the Spider Spins: Essays on Nietzsche's Critique and Use of Language, Berlin/Boston: Walter de Gruyter, 2012.

2. WWV I $\$ 9$, p. 47. La sigla WWV se refiere a A. Schopenhauer, Die Welt als Wille und Vorstellung, en Sämtliche Werke, ed. Arthur Hübscher, Wiesbaden: Brockhaus, 1949. [Puede consultarse también A. Schopenhauer, El mundo como voluntad y representación, trad., introd. y notas de Pilar López de Santa María, Trotta, Madrid, vol. I: ${ }^{2} 2009$; vol. II: ${ }^{32009] . ~}$

3. WWV I $₫ 9$, p. 47.

4. WWV I $\$ 8$, p. 46.

5. WWV I $₫ 8$, p. 44.

6. WWV I $₫ 8, \mathbb{1} 10, \mathbb{} 12$.

7. WWV I $\$ 12$.

8. WWV I $\$ 8$, p. 43. 
Según Schopenhauer, la conciencia es, en primer lugar, «conciencia animal»9. Los animales poseen la capacidad de reconocer intuitivamente las relaciones primarias de causa y efecto, y hacer uso de esta capacidad es equivalente a la representación de objetos en el espacio y el tiempo. Por lo tanto, debemos ver a los animales no humanos como seres conscientes. Representación intuitiva de objetos - es decir, conciencia inmediata - es lo mismo que la conciencia en su nivel más bajo. Sin embargo, la conciencia humana, como el más alto grado de "conciencia», debe ser definido como «reflexión", que no es más que «abstracta» o «conceptual» representación por medio de los signos lingüísticos, sobre la base de las representaciones intuitivas ${ }^{10}$.

4. En la visión de Schopenhauer, los signos tienen un significado porque expresan conceptos, y los conceptos tienen un significado porque expresan intuiciones. Los conceptos son «representaciones de representaciones» ${ }^{11}$. Un concepto puede ser una representación de otros conceptos, pero será un concepto vacío si estos otros conceptos no son representaciones de las intuiciones. Schopenhauer escribe: «Los conceptos son diferentes de las representaciones intuitivas que están en una relación necesaria con ellos, y sin ellas no serían nada. Esta relación, por consiguiente, constituye su entera naturaleza y existencia. Reflexión (es decir, representación conceptual) es necesariamente copia o repetición del originalmente presentado mundo de la intuición, aunque una copia de un tipo bastante especial en un material completamente heterogéneo» ${ }^{12}$. En consecuencia, una proposición es «verdadera» cuando sus signos y su relación entre ellos expresa conceptos que se refieren a intuiciones. Dicho de otra manera, si queremos que el lenguaje describa el mundo exterior, nuestros conceptos y signos deben hacer referencia en última instancia a las percepciones, y si queremos que el lenguaje describa nuestro mundo interior, nuestros conceptos y signos en última instancia deben referirse a los sentimientos o sensaciones (internas).

5. Aunque Schopenhauer no utiliza la terminología nietzscheana de «simplificar» $\mathrm{y}$ «simplificación», sus puntos de vista sobre los conceptos y la formación de conceptos implican (según parece) precisamente lo que Nietzsche quiere decir con estos términos.

a) Según Schopenhauer, un concepto es una representación «general»o «universal» no porque sea "abstraída de varios objetos», sino porque deja el particular indeterminado y, a causa de esto, puede adaptarse y aplicarse a varios objetos. Dicho de otro modo, la generalidad es la característica esencial de los conceptos, pero la generalidad significa indeterminación, es decir, una representación simplificada de otras representaciones que es siempre «incongruente» con los objetos reales presentados en el espacio y el tiempo. Schopenhauer escribe:

... puede haber conceptos con los que se piense solo un objeto real, único, pero que sin embargo son representaciones abstractas y generales, y de ninguna manera representaciones particulares y intuitivas. Tales son, por ejemplo, el concepto de una ciudad determinada y localizable geográficamente. Aunque solo esta ciudad

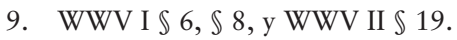

10. Cf. WWV I $\$ 9$.

11. WWV I $\$ 9$, p. 49.

12. WWR I $\$ 9$, p. 48 . 
se piense a través de él, sin embargo, podría ser también posiblemente adecuado para varias ciudades diferentes en solo algunos detalles. Así, un concepto tiene generalidad no porque se abstrae de varios objetos, sino a la inversa, porque la generalidad, es decir, la no determinación de lo particular [Nichtbestimmung des Einzelnen] es esencial para el concepto como representación abstracta de lo particular, con lo que cosas diferentes se puede pensar a través del mismo concepto ${ }^{13}$.

Schopenhauer interpreta esta indeterminación esencial de todos los conceptos como «incongruencia» en relación a la intuición ${ }^{14}$. Los conceptos tienen sentido porque sacan sus contenidos a partir de intuiciones, pero nunca son «congruentes» con la riqueza de una sola representación intuitiva ${ }^{15}$. El conocimiento conceptual «se aproxima» a las representaciones intuitivas, pero solo en el mismo sentido en que «un mosaico se aproxima a una pintura» ${ }^{16}$. Las diferenciaciones más sutiles y los matices permanecen siempre intuitivos. Los conceptos son demasiado ásperos e indeterminados para «llegar» a los complejos «matices de diferencia» que pertenecen a las percepciones y sensaciones internas: simplemente no pueden expresarlos ${ }^{17}$.

b) Por otra parte, el «rango», «extensión» o «esfera» de todo concepto siempre tiene "algo en común con las esferas de otros conceptos» ${ }^{18}$. Los límites de nuestros conceptos no son fijos ni inmunes a las «esferas» de otros conceptos y, por tanto, son siempre equívocos. Los conceptos-esferas (die Begriffssphären) "se superponen entre sí de muchas maneras», de modo que en el razonamiento tendemos a pasar arbitrariamente de una esfera a otra, y «la naturaleza de la mayoría de los argumentos científicos, en particular de la demostración filosófica, no es en el fondo diferente a esto» ${ }^{19}$.

6. Teniendo en cuenta que los conceptos y sus signos son simplificaciones indeterminadas y equívocas de intuiciones, nunca pueden producir una representación adecuada de las cosas «en sí mismos». La conciencia humana es una «superficie» y capta solo la «superficie» de las $\operatorname{cosas}^{20}$. La idea de que la simplificación a través de conceptos y signos es esencial para la conciencia humana, explica una de las principales consecuencias del uso que hace Schopenhauer de la imagen metafórica de la conciencia como una «superficie» ${ }^{21}$ : el mundo representado por la conciencia humana es «el trabajo de Maya, el mundo de las sombras de Platón» ${ }^{22}$, «una ilusión inestable e inconstante sin sustancia, comparable a la ilusión óptica y al sueño, un velo que envuelve la conciencia humana, algo de lo que es igualmente falso e igualmente cierto decir que es y que no es» ${ }^{23}$. Si el espacio, el tiempo y la causalidad son solo la forma subjetiva de la intuición de los

13. WWV I $\$ 9$, p. 50 .

14. WWV I $\$ 13$.

15. WWV I $\$ 13$.

16. WWV I $\$ 13,70$, cf. WWV $\$ 12$.

17. Cf. WWV I $\$ 12$.

18. WWV I $\$ 9$, p. 50.

19. WWV I $\$ 9$, p. 59.

20. WWV II $₫ 14$, WWV I $₫ 17$, y WWV II $₫ 25$.

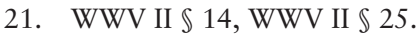

22. WWV I Anhang, p. 498.

23. WWV I Anhang, p. 497. 
objetos, el mundo como intuitivamente representado en la conciencia animal es ya «mero fenómeno», es decir, una superficie cortada de la naturaleza interna de las cosas; pero como los conceptos derivan su sentido de la intuición y no son más que «representaciones de representaciones», ese mismo mundo representado por la conciencia humana (es decir, la razón y el lenguaje) sigue siendo él mismo "superficie» ${ }^{24}$ que se simplifica aún más por el uso de los conceptos y las palabras. Nuestro mundo de los fenómenos no sería más que una «superficie» aun cuando la ciencia pueda resolver, en conceptos y signos, su etiología completa ${ }^{25}$. El schopenhaueriano punto de vista sobre los conceptos y los signos es parte de su reformulación de la distinción de Kant entre «fenómenos» y «cosas en sí mismas».

Me refiero ahora al nietzscheano punto de vista sobre los conceptos y signos.

Nietzsche parece estar de acuerdo con Schopenhauer en varios puntos esenciales: él también cree que la conciencia humana depende de la formación de los conceptos y el uso de signos; para él, también, la conciencia y el lenguaje (humanos) son prácticamente idénticos; para él, también, la conciencia específicamente humana es la representación que se complementa con la conceptualización y el uso de $\operatorname{signos}^{26}$. Así, la cuestión es determinar cómo exactamente Nietzsche se separa de Schopenhauer, y si su diferencia de Schopenhauer implica una nueva interpretación de las tesis que parece haber tomado de él.

1. Primero, Nietzsche parece estar de acuerdo con Schopenhauer en que las palabras son «signos de los conceptos». En Más allá del bien y del mal, Nietzsche escribe: «Las palabras son signos acústicos para conceptos, los conceptos, sin embargo, son más o menos determinados signos pictóricos para sensaciones que ocurren juntos y se repiten con frecuencia, para grupos de sensaciones» ${ }^{27}$. Totalmente de acuerdo con su sentido tradicional, la palabra «signo» (Zeichen) en las expresiones «signos acústicos» (Tonzeichen) y «signos pictóricos» (Bildzeichen) parece querer decir una abreviatura que nos permite expresar o designar algo, zu bezeichnen. Así, las palabras son abreviaturas que indican, por lo que expresan conceptos, y los conceptos son abreviaturas que indican, por lo que expresan sensaciones ${ }^{28}$.

2. Al igual que Schopenhauer, Nietzsche liga conciencia, razón, concepto, signo y comunicación. Pero el primer punto en el que se separa radicalmente de Schopenhauer concierne precisamente a la comunicación. Para Nietzsche, todos

24. Cf. WWV II $\$ 25$.

25. Cf. WWV I $\$ 17$

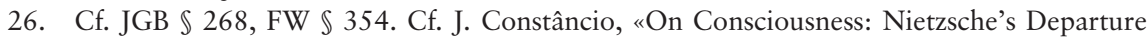
from Schopenhauer», cit., pp. 1-10.

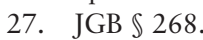

28. Sobre el concepto de «signo» (Zeichen) en Nietzsche, cf. Josef Simon, «Das Problem des Bewusstseins bei Nietzsche und der traditionelle Bewusstseinsbegriff», en M. Djuriç y J. Simon, Nietzsche in der Diskussion, Zur Aktualität Nietzsches, vol. II, Würzburg: Königshaus, 1984, pp. 1733, y Werner Stegmaier, «Nietzsches Zeichen»: Nietzsche-Studien 29 (2000), 41-69. Cf. J. Constâncio, «On Consciousness: Nietzsche’s Departure from Schopenhauer», cit., pp. 30-37. 
los signos son verdaderamente «signos de comunicación» $»^{29}$ y la conciencia humana es en sí misma una «habilidad para comunicarse» ${ }^{30}$. ¿Pero por qué son todos los signos «signos de comunicación»?

a) En primer lugar, la idea de Nietzsche parece ser que los conceptos presuponen un contexto, es decir, que un concepto es imposible fuera de una multiplicidad o constelación de conceptos. Para que un concepto tenga sentido, debe diferenciarse de otros conceptos, y por lo tanto la comprensión de un concepto equivale a la comprensión de su relación con otros conceptos. Pero los contextos en los que nuestros conceptos emergen son siempre ya contextos sociales. No emergen de un capullo solipsista. En consecuencia, los signos que expresan conceptos son siempre ya signos que uno usa como «animal social $»^{31}$ : pertenecen al medio social de la comunicación y son de hecho «signos de comunicación».

b) Por lo tanto, Nietzsche invierte la relación entre reflexión y comunicación. Al definir el lenguaje y el uso de signos como «el instrumento necesario de la razón», Schopenhauer aún concibe la razón (o la «reflexión») como algo intrínsecamente individual que de alguna manera precede a la comunicación - mientras para Nietzsche, la comunicación precede a cada uso individualizado de la razón (o «reflexión») - . En la obra madura de Nietzsche, «reflexión» —el espejo-función de la conciencia, nuestra capacidad de «saber que sabemos»" ${ }^{32}$ - se presenta como algo «desarrollado solo bajo la presión de la necesidad de comunicar ${ }^{33}$. Se da la primacía a la comunicación. La formación de conceptos y signos se orienta principalmente hacia la comprensión mutua dentro de los contextos sociales, y su contenido nunca pierde su relación con la comunicación, incluso a los más altos niveles de abstracción ${ }^{34}$.

c) Por otra parte, Nietzsche ya no identifica la conciencia humana con la «razón». Hay una razón inconsciente que consiste en la «inteligencia» (Klugheit) del instinto, es decir, del cuerpo u organismo. Así, en La gaya ciencia, Nietzsche distingue entre «razón» y «la toma de conciencia de la razón»" En Así habló Zaratustra se hace la famosa distinción entre la "gran razón» del cuerpo y la «pequeña razón» de la llamada «alma»" Su idea es, por supuesto, que lo que llamamos «razón» no es necesariamente una actividad consciente de nuestro organismo, y de hecho la racionalidad de nuestros pensamientos conscientes presupone la racionalidad de nuestros instintos. Esta es la idea que hay detrás de la tesis propuesta en Más allá del bien y del mal, de que «el 'instinto' es la forma

29. Mittheilungszeichen, $\mathrm{FW} \$ 354$.

30. Mittheilungs-Fähigkeit, FW $\mathbb{3} 354$.

31. FW $\$ 354$.

32. Cf. KSA IX 438: 10[101].

33. FW $\$ 354$.

34. Incluso en las proposiciones matemáticas, por ejemplo, cualquier nuevo pensamiento está generado por un impulso a simplificar la realidad y volverla familiar y comprensible - y, por tanto, por un impulso que implícitamente busca una mejor comunicación: cf., por ejemplo, KSA XI 209: 26[227] y JGB \$21. Cf. Werner Stegmaier, «Nietzsches Zeichen»: Nietzsche-Studien 29 (2000), 62-64, y J. Constâncio, «On Consciousness: Nietzsche's Departure from Schopenhauer», cit., p. 34.

35. FW $\$ 354$.

36. Za I, «Los despreciadores del cuerpo». 
más inteligente de inteligencia descubierta hasta ahora ${ }^{37}$.

Estas son ya diferencias decisivas respecto de los puntos de vista de Schopenhauer, que ahora debemos tratar de interpretar en relación con el tema de la «simplificación» y, por tanto, de los «signos».

3. Como «capacidad de comunicación», la conciencia humana es un «aparato de simplificación $»^{38}$ y un Zeichen-Apparat, «un aparato de signos» ${ }^{39}$. La «reducción de las experiencias a signos» llevada a cabo por este «aparato de signos» es, para Nietzsche, «la superioridad del hombre $»^{40}$. Como es bien sabido, Nietzsche critica la «sobrestimación absurda de la conciencia» que transforma la conciencia en «una unidad, una entidad» ${ }^{41}$. Más allá de esta «sobreestimación absurda», Nietzsche concibe la conciencia como un estado intermitente del organismo ${ }^{42} \mathrm{y}$, sobre todo, como una «herramienta» de las pulsiones y los afectos, es decir, de los instintos. Esto rebaja el poder de la conciencia a algo de «quinta importancia en comparación con el valor de los instintos» ${ }^{43}$. Sin embargo, esta «herramienta» está lejos de ser totalmente impotente. Toda nuestra vida social depende de ella; y todas las tareas filosóficas, como por ejemplo la tarea de Nietzsche de «revalorización de todos los valores», serían simplemente carentes de sentido si los pensamientos conscientes y sus conceptos y signos fueran simplemente impotentes. Su poder es limitado, pero participan en la «lucha» que ocurre dentro del organismo (o que es el organismo). Los pensamientos conscientes son «herramientas» de los instintos en esta lucha, pero el hecho de que sus conceptos y signos son nuevas simplificaciones $-\mathrm{y}$ por tanto interpretaciones nuevas y más simples de nuestra experiencia - implica que lleven a cabo cambios en esta lucha. Ellos no pueden controlarla, pero la enriquecen. En otras palabras, los pensamientos conscientes emergen de pulsiones previamente activas y siempre permanecen unidos a pulsiones que luchan entre sí dentro del organismo, pero añaden algo nuevo a esta lucha - algo que tiene cierto nivel de eficacia en la medida en que puede ser «incorporado» o «asimilado» por el organismo.

Además, Nietzsche considera que este impacto de la conciencia sobre la vida instintiva del organismo debe ser valorado ambivalentemente. Por un lado, la conciencia es «un síntoma de la imperfección relativa del organismo [humano]» ${ }^{44}$; por otro lado, la conciencia es parte de las capacidades extraordinarias del organismo humano. Como ya he dicho, «la superioridad del hombre» ${ }^{45}$ depende de la capacidad simplificadora y interpretativa del organismo humano; de la su conciencia entendida como «espíritu» (Geist), es decir, como el tipo de «prudencia», «paciencia», «astucia», «creatividad», «simulación» y «dominio de sí mismo», que solo la formación de conceptos y el uso de los signos lingüísticos hace posible ${ }^{46}$.

37. JGB $\$ 218$.

38. KSA XI 434: 34[46].

39. KSA XI 464: 34[131].

40. KSA XI 464: 34[131]

41. KSA XIII 330: 14[146].

42. Cf. FW $\mathbb{} 11$.

43. AC $\$ 39$.

44. AC $\$ 14$

45. KSA XI 464: 34[131].

46. Por ejemplo, JGB $\mathbb{4} 44$, GD «Streifzügen eines Unzeitgemässen» $\$ 14$. 
4. a) $\mathrm{Al}$ igual que Schopenhauer, Nietzsche considera, además, que los signos tienen un significado porque expresan conceptos, y los conceptos tienen un significado porque expresan «intuiciones», es decir, sensaciones (externas o internas). En vista de lo que acabamos de ver, «expresar» aquí significa abreviar y simplificar. Esto está implícito en la idea, mencionada al principio, de que las palabras son «los signos acústicas de los conceptos» y los conceptos son «signos pictóricos de sensaciones» ${ }^{47}$. Las palabras nos permiten comunicar conceptos de forma rápida y sin reflexión, y los conceptos nos permiten comunicar sensaciones de forma rápida y sin tener que revivir nuestras experiencias. Esto, sin embargo, es un tipo de expresión que solo es posible porque los conceptos simplifican las sensaciones y las palabras simplifican los conceptos; $y$, de hecho, solo es posible porque hay una pulsión de simplificación, sin la cual no habría conciencia en absoluto. Nietzsche escribe en el Nachlass: «... en nuestro espíritu consciente (Geist) debe haber sobre todo una pulsión para excluir, para alejar, una pulsión de selección - que permite solo a ciertos hechos presentarse a ella $»^{48}$. Como un «aparato de simplificación», la conciencia es casi idéntica a esta pulsión. Se añade también, que la simplificación busca la selección. Ya en Leibniz y Kant, la formación de conceptos es una selección de «marcas» (notae, Merkmale) que la conciencia transforma en representaciones generales (notiones comunes). Al igual que Schopenhauer, Nietzsche ve esta transformación como un proceso de simplificación, o de «no-determinación de lo particular» (Nichtbestimmung des Einzelnen), pero añade que tal es el resultado de la actividad de una pulsión. Por otra parte, puesto que él también piensa que la conciencia tiene por objeto la comunicación, interpreta esta simplificación y generalización como un proceso social de abreviación, es decir, de creación de signos de comunicación.

b) Una de las mayores innovaciones de Nietzsche a este respecto es su tesis de que los pensamientos mismos (y no solo las palabras) son signos, a saber, signos de las relaciones entre las pulsiones o los instintos. Escribe en el Nachlass: «Un pensamiento, no menos que una palabra, es solo un signo: no se puede hablar de congruencia entre el pensamiento y la realidad» ${ }^{49}$. No es solo el caso de que «la historia de la lengua» sea «la historia de un proceso de abreviación», como escribe Nietzsche en Más allá del bien y del mal ${ }^{50}$. Los pensamientos mismos —es decir, todos nuestros conceptos y representaciones conscientes- son «abreviaturas», «resúmenes», «signos» de lo que perciben las pulsiones. Los signos lingüísticos, de su parte, fijan conceptualizaciones, es decir, son abreviaturas que dan forma a las abreviaturas que se producen en el medio de la comunicación.

Esta es la razón por la cual, para Nietzsche, la conciencia es siempre una «superficie» ${ }^{51}$. Lo que quiere decir con esto no es solo que un estado mental consciente siempre expresa la «situación total de poder» (die Macht gesammteLage) del organismo ${ }^{52}$; quiere decir también que la expresión conceptual de esta

47. JGB 268.

48. KSA XI 464: 34[131].

49. KSA IX 263: 6[253].

50. JGB $\$ 268$.

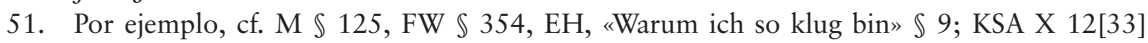
y 24[16]; KSA XI 26[92], 26[94] y KSA XII 1[61].

52. KSA XII 26: 1[61]. 
«situación de poder» siempre se compone de signos o relaciones de signos $^{53}$. Esta es la razón por la que ve todos los morales, religiones y filosofías como «signos-lenguajes» (Zeichen-Sprachen) de las pulsiones y los afectos, es decir, como «síntomas» de la actividad instintiva ${ }^{54}$. Los pensamientos de Nietzsche y sus conceptos filosóficos no son, por supuesto, una excepción de esto.

5. a) Por lo tanto, los conceptos son representaciones generales, pero su generalidad resulta de un proceso de selección, simplificación y abreviación. En Más allá del bien y del mal Nietzsche escribe: "Usando las mismas palabras no es suficiente para que la gente llegue a entenderse entre sí: tienen que utilizar las mismas palabras también para la misma especie de experiencias internas y, en última instancia, tener la misma experiencia en común» ${ }^{55}$. Las palabras y los conceptos son representaciones generales para fijar lo que es común a una multiplicidad de experiencias internas, fijando así lo que es común a una multiplicidad de «cosas» —o, más precisamente, lo que es común a una multiplicidad de sensaciones externas que se convierten en «cosas» $y$ «propiedades» para nosotros, justamente en la medida en que las conceptualizamos y nombramos ${ }^{56}$. Esto resulta de un proceso de selección, simplificación y abreviación que excluye lo que es único o individual en una sensación. Así, al igual que Schopenhauer, Nietzsche ve la generalización como una «no-determinación del particular», y también pone de relieve la incongruencia entre nuestros conceptos (o representaciones generales) y nuestras experiencias internas y sensaciones externas. En el Nachlass, escribe, por ejemplo: «Un concepto es una invención a la que nada corresponde en su totalidad, sino muchas cosas un poco $»^{57}$.

b) Sin embargo, la idea de Nietzsche sobre la generalización incluye una diferencia muy importante respecto de Schopenhauer. Nietzsche rechaza la oposición directa de Schopenhauer entre conceptos e intuiciones. Al igual que Kant, él cree que siempre hay un tercer elemento entre intuiciones y conceptos; es decir, que formamos conceptos sobre la base de las intuiciones en un proceso en el que en primer lugar construimos o dibujamos una imagen pre-consciente (Bild) del concepto: un «esquema» $(\text { Schema })^{58}$. Nuestro concepto «árbol», por ejemplo, no se basa simplemente en ciertas sensaciones, sino también en cómo somos capaces de elaborar y simplificar las sensaciones al imaginar o fantasear una imagen que es solamente una imagen de «una aproximación de un árbol (ein Ungefähr von Baum) $»^{59}$; en términos kantianos, al proporcionar una imagen que no es una imagen de un árbol en particular, sino más bien de la misma «regla» que se aplicará en el uso de la representación general «árbol». No sin razón, Hannah

53. Por ejemplo, KSA XI 174: 26[92].

54. Por ejemplo, BGE $\$ 187$.

55. JGB $\$ 268$.

56. Por ejemplo, KSA XII 395: 9[106]: «... woher könnten wir wissen, daß es Dinge giebt? Die 'Dingheit' ist erst von uns geschaffen».

57. KSA XI 464: 34[131].

58. Cf. KSA IX 448: 11[18], KSA XI 175: 26[94], KSA XI 505: 34[249], KSA XI 562: 36[26], KSA XI 597: 38[2], KSA XI 687: 41[11], KSA XII 194: 5[22], KSA XII 389: 9[97], KSA XIII 53: 11[113], KSA XIII 333: 14[152], KSA XIII 336: 14[153], KSA XIII 458: 15[90].

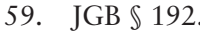


Arendt ha definido el «esquema» kantiano como «una imagen general» ${ }^{60}$. Un concepto tiene sentido si se refiere a esa «imagen general», es decir, si se refiere a intuiciones a través de un «esquema» o una «imagen general». Esta imagen es lo que permite al concepto funcionar como una marca o característica que, por así decirlo, proyectamos en nuestras sensaciones y luego percibimos como si se tratara de una marca o característica intrínseca y real de lo que se da en nuestras sensaciones. Y esto, por supuesto, es como nuestro «mundo de superficie y signo» ${ }^{61}$; el mundo conceptualizado y simbólico en el que nuestras vidas tienen lugar se convierte, para nosotros, en el mundo más «real», de hecho, en la única realidad a la que significativamente podemos referirnos ${ }^{62}$.

c) Por otra parte, debe quedar claro que el «esquematismo» de Nietzsche se opone radicalmente al de Kant en un punto muy importante. Contra Kant, Nietzsche insiste en el carácter arbitrario, totalmente contingente de nuestros esquemas, así como en la naturaleza convencional de los conceptos lingüísticos y de los signos que los fijan. O, dicho de otro modo, Nietzsche extrae la consecuencia natural de la tesis de Kant de que los esquemas son producto de la imaginación. Los conceptos son algo que nuestro organismo inventa, crea, fabula, novela en su interacción social; algo que nace, en primer lugar, de la «artística» imaginación de nuestra fisiología y de la capacidad de nuestro espíritu para crear signos en el medio social de la comunicación. En este sentido, «la gente es mucho más artista de lo que piensa» ${ }^{63}$, como dice Nietzsche en Más allá del bien y del mal. O, como escribe en una nota póstuma, los seres humanos y los pueblos que inventan conceptos son «Abstraktions-Künstler», «artistas de la abstracción» ${ }^{64}$.

d) Dado que la abstracción de las representaciones generales o conceptos de las sensaciones es una actividad «artística» de nuestro organismo, debemos concluir que los procesos de selección, simplificación y abreviación que dan lugar a conceptos y signos son también procesos de falsificación. Como Nietzsche escribe, por ejemplo, en La gaya ciencia, «... todo tomar conciencia implica una corrupción inmensa y profunda falsificación, superficialización y generalización» ${ }^{65}$. «iEn qué extraña simplificación y falsificación viven las personas ${ }^{66}$, exclama en Más allá del bien y del mal. No solo el «mundo verdadero» de Platón y del cristianismo es «eine Fictions-Welt», un «mundo ficticio» ${ }^{67}$; nuestro mundo fenoménico - «el mundo que es relevante para nosotros ${ }^{68}$, ya sea en la vida cotidiana o en la ciencia- es también, en otro sentido, un «mundo ficticio» ${ }^{69}$. Podemos, y de hecho debemos, distinguir entre los conceptos que se refieren a sensaciones y los conceptos que son simplemente inventados, como Kant y Schopenhauer han

60. Cf. H. Arendt, Lectures on Kant's Political Philosophy, Chicago: The University of Chicago Press, 1992, p. 81.

61. FW $\$ 354$.

62. Por ejemplo, KSA XII 396: 9[106].

63. JGB $\$ 192$.

64. KSA XII 237: 6[11].

65. FW $\$ 354$.

66. JGB $₫ 24$.

67. AC $\$ 15$.

68. JGB $₫ 34$.

69. A $\ 15$, JGB $\$ 34$, KSA XII 396: 9[106]. 
distinguido. Sin embargo, tanto nuestros «conceptos empíricos» como nuestros conceptos con los que esquematizamos el espacio y el tiempo (es decir, las «categorías») también son «ficciones», simplificaciones selectivas y abreviaciones. Por lo tanto, como escribe Nietzsche en Más allá del bien y del mal, «la falsedad del mundo en el que creemos vivir es el hecho más seguro y sólido que nuestros ojos pueden captar» ${ }^{70}$.

6. La idea de la falsificación y la tesis de que la conciencia es una «superficie» y nuestro mundo fenoménico un "mundo de superficie y signo» ${ }^{71}$ parecen dar a entender que Nietzsche está de acuerdo con Schopenhauer en que nuestro mundo fenoménico no es más que una «ilusión», un «sueño», etc. Y, sin embargo, esta no es en absoluto la opinión de Nietzsche. Al repensar sensación, percepción, interpretación, esquematización, conceptualización y conciencia en términos de relaciones de signos, Nietzsche intenta, precisamente, superar la concepción schopenhaueriana de «ilusión». Las relaciones de signos no se refieren a una «cosa en sí» o a un «mundo verdadero» más allá de las apariencias. Teniendo en cuenta que los conceptos son signos, no deben ser vistos como «representaciones» o «imágenes» de «las cosas mismas». Lo que «falsifican» no es un mundo en sí mismo con sus propiedades intrínsecas, sino más bien nuestras pulsiones y afectos. La medida en que nuestros conceptos son inseparables de sus esquemas, son, en cierto sentido, «imágenes»; pero estas imágenes, como escribe Nietzsche en Más allá del bien y del mal, son «Bildzeichen», «signos pictóricos», «imágenes-signo»72 de nuestra vida instintiva. Lo que estas imágenes esquematizan es doble: en primer lugar, se esquematizan las relaciones entre nuestras pulsiones y afectos, esto es, nuestras experiencias internas; en segundo lugar, se esquematizan las sensaciones externas. Nuestros sentidos, no menos que nuestra conciencia, pueden ser descritos como un «aparato de simplificación» ${ }^{73}$. Así, el «caos de sensaciones» es ya un producto simplificado de la actividad de nuestros sentidos, que llega a simplificarse aún más por la actividad preconsciente de esquematización de nuestros impulsos y es aún más simplificado, «recortado», «logicizado» y «falseado» por nuestros conceptos y signos conscientes ${ }^{74}$. Así lo señala Nietzsche:

Lo opuesto de este mundo fenoménico, [es decir, del mundo como lo conocemos a través de los pensamientos conscientes], no es «el mundo verdadero», sino el mundo sin forma, informulable del caos de nuestras sensaciones - por lo tanto, un tipo diferente de mundo de los fenómenos, no «cognoscible» para nosotros ${ }^{75}$.

Si esto es así — si nuestros conceptos son signos que abrevian tanto nuestras experiencias internas como externas-, entonces es al menos muy plausible que nuestra concepción de un «mundo verdadero» y una «cosa en sí» sea una ficción más de la nuestra conciencia, y una ficción a la que ninguna sensación puede ofrecer un fundamento o apoyo. Todo lo que creamos que existe «más allá» de

70. JGB $\$ 34$

71. FW $\$ 354$

72. JGB $\mathbb{2} 268$.

73. KSA XII 434: 34[46].

74. Cf. KSA XII 396: 9[106].

75. KSA XII 396: 9[106]. 
nuestra experiencia interior y exterior es, de hecho, solo una reificación de un concepto, nada más que un concepto que creamos de dentro de nuestro mundo fenoménico y conceptual. En lugar de postular la oposición de fenómeno/cosas en sí mismas, como Kant y Schopenhauer, debemos entender la naturaleza misma, la vida misma, nuestros instintos inconscientes y nuestros pensamientos conscientes y conceptuales como elementos de un continuo (continuum). De esta manera, la «falsedad del mundo en el que pensamos vivir» ${ }^{76}$ se convierte en algo muy diferente de una mera «ilusión». "Falsificación» ya no es una creación de la «ilusión», sino solo de signos. Así se puede abolir el «mundo verdadero»; y, como Nietzsche ha escrito, «con el mundo verdadero también hemos suprimido el mundo ilusorio» ${ }^{77}$, es decir, hemos transformado el fenómeno en una dimensión de lo real.

Resumiendo los principales puntos de discrepancia de Nietzsche respecto de Schopenhauer sobre los conceptos y los signos, podemos ver entonces por qué la filosofía de Nietzsche es ya, en muchos aspectos, «contemporánea», «actual», o por lo menos no-cartesiana e no-metafísica: i) Nietzsche rechaza el punto de vista solipsista y sitúa la formación de signos en el medio de la comunicación; ii) describe el proceso de generalización como un proceso llevado a cabo por pulsiones orgánicas; iii) describe este proceso como una «artística» creación de nuestro organismo, por lo que subraya la contingencia radical de nuestras conceptualizaciones; $i v$ ) rechaza la oposición de los fenómenos y las cosas en sí mismas: por un lado, interpreta el mundo de los fenómenos como una ficción, pero, por el otro, interpreta esta ficción como una dimensión de lo real.

76. JGB $₫ 34$.

77. GD «Wie die 'wahre Welt' endlich zur Fabel wurde». 